FSS

González-Nuevo, C., Cuesta, M., \& Muñiz, J. (2021). Concern about appearance on Instagram and Facebook: Measurement and links with eating disorders. Cyberpsychology: Journal of Psychosocial Research on Cyberspace, 15(2), Article 9. https://doi.org/10.5817/CP2021-2-9

\title{
Concern About Appearance on Instagram and Facebook: Measurement and Links With Eating Disorders
}

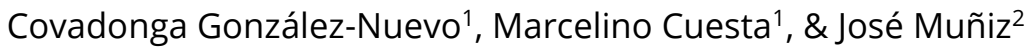 \\ 1 University of Oviedo, Oviedo, Spain \\ ${ }^{2}$ Nebrija University, Madrid, Spain
}

\begin{abstract}
Appearance-related use of Social Networks (SNs) exhibits a clear relationship with the risk of eating disorders (ED). To determine which components of appearance-related use are most important for the detection and prediction of ED, it is necessary to measure concern about appearance on SNs in detail. The two main objectives of this study are to develop and validate the Concern about appearance on SNs scale (CONAPP), and to analyze the relationships between concern about appearance on SNs and the risk of ED. A total of 576 Spanish women over 18 years old, with an average age of $28.88(S D=11.14)$, participated in an online survey. We evaluated the use of the two most-commonly used SNs (Facebook and Instagram), concern about appearance on SNs, and eating attitudes (the latter through the Eating Attitudes Test-26). The psychometric properties of the CONAPP questionnaire were excellent. Strong positive correlations were found between concern about appearance on SNs and risk of ED. The pattern differed between users of Facebook and Instagram. Instagram users were younger, demonstrated higher risk of EDs and higher scores in the CONAPP questionnaire. The implications of the results for the prevention of ED are discussed.
\end{abstract}

Keywords: Eating disorders risk; social media; appearance comparison; body image; Facebook use; Instagram use

\section{Introduction}

The internet and social networks (SNs) are widely used. There are an estimated 4.388 billion internet users around the world, representing 57\% of the total population, and 3.484 billion SN users (Global Digital Report, 2019). The most widely-used SN is Facebook (FB), which is generally used by all ages (Smith \& Anderson, 2018). However, Instagram (IG) is the most widely-used highly-visual social media (Global Digital Report, 2019), and is particularly popular with 18 to 25 year-olds (Smith \& Anderson, 2018). Although these SNs have similar structures, IG places more importance on images in its publications, while FB emphasizes text. Thus, IG can be considered highly-visual social media (Marengo et al., 2018).

The widespread use and implementation of SNs has triggered interest from behavioral researchers. Eating disorders (ED) are one of the most widely-studied disorders related to SNs due to appearance comparison factors (Burnell et al., 2019; Fardouly \& Vartanian, 2015). Appearance comparison on SNs is often accompanied by feedback (i.e., comments or likes), which may be positive or negative (Burnell et al., 2019; Fardouly \& Vartanian, 2015). It is this negative feedback that is related to the risk of EDs (Hummel \& Smith, 2015; Tiggemann \& Barbato, 2018). 
Most studies confirm that there is a relationship between ED risk and SN use, but the strength of this relationship depends largely on how SN use is measured. To date, research evaluating this relationship has focused on frequency of use rather than motives for use. This may be a problem because frequency of use alone is not a reliable predictor of ED, whereas photo-based behaviors are. The present study will attempt to overcome this problem, designing a new specific measuring instrument for the evaluation of concern about appearance on SNs. The instrument will be validated initially only with women, as they have a higher prevalence of ED (Striegel-Moore et al., 2009). Within this context, the general objective of the present study is to analyze the relationship between concern about appearance on SNs and the risk of ED. This general objective is broken down into two more specific objectives. The first focuses on the development of a new measuring instrument to assess concern about appearance on SNs. The second specific objective is to study the relationships between concern about appearance on SNs and the risk of eating disorders in detail. We expect this relationship to be positive, in line with previous studies (Mingoia et al., 2017).

\section{Concern About Appearance on SNS}

Appearance comparison has been studied in connection with traditional media and the thin ideal-body it shows, which has caused body dissatisfaction (Grabe et al., 2008). However, SNs have been proven to produce more body dissatisfaction and higher risks of ED than traditional media (Cohen \& Blaszczynski, 2015). The use of SNs in relation to the risk of EDs has been measured in various ways. Most studies, according to Holland and Tiggemann (2016), have measured overall use as frequency of use, which is an insufficiently detailed measure. This is because frequency of use is not a faithful reflection of how SNs have been used. For example, knowing that someone used SNs for one hour does not tell us whether they have published a retouched photo, or the reasons for publishing it. In order to determine whether someone's use of SNs is maladaptive, we need questionnaires that are more specific about that use.

In this regard, appearance-related use on SNs are those activities that are specifically related to appearance (e.g., looking at photographs) (Mingoia et al., 2017). The difference between appearance-related use and concern about appearance on $\mathrm{SNs}$ is in the consequences of the use. Appearance-related use of SNs is inherent in the use of SNs, as much of the functionality is based on exposure to photos and numerical indicators of social acceptance (e.g., likes). However, the problem arises when that use begins to cause excessive worry. In short, concern about appearance on SNs is defined as preoccupation about physical appearance (e.g., how I look in a photograph) or social appearance (e.g., having more likes than other photos do) on SNs which has negative consequences on a person's life. As far as we are aware, ours is the first questionnaire to evaluate this.

One questionnaire that does partly evaluate appearance-related use is the Facebook Questionnaire (FBQ) from Meier and Gray (2014), focused on the use of images. This questionnaire, besides asking about overall FB use, asks eight specific questions about photo-based activity (e.g., updating profile photos, viewing friends' photos of themselves or commenting on friend's photos). This questionnaire assesses appearance-related use, or photobased activity on SNs, but it does not address concern about appearance, because it does not assess whether that photo-based activity is the cause of preoccupation, which would be concern about appearance. The FBQ was used by Cohen et al. (2017) to measure both overall use and appearance-related use. They found that appearancerelated use on SNs rather than overall use was associated with body dissatisfaction and thin ideal internalization. Another study that included a subscale on appearance-related use on SNs was McLean et al. (2015), which, in addition to measuring active FB use, included items about the frequency of taking selfies, sharing selfies, photo investment, and photo manipulation. This questionnaire is closer to concern about appearance on SNs as it includes the subscales Photo investment and Photo manipulation which include the use of filters and people's emotional investment in SNs. However, it does not include other aspects of concern about appearance on SNs such as planning photos or concern about feedback.

In summary, the use of SNs has been measured in various ways, and appearance-related use is most closely related with ED risk. In this study, we suggest that appearance-related use is inherent in SNs and is not negative in itself, which is why we developed the concept of concern about appearance on SNs. Based on the literature, we differentiate four areas, that will be captured in the CONAPP scale we developed. These are Photo Preparation, Social Comparison, Strong concern about social media presence, and Influence of SN involvement in day-to-day life. These four areas may seem different, but they refer to the same construct, as they all involve behaviors of concern 
about appearance on SNs. Because of this, and despite theorizing the existence of these four areas that might be possible to interpret independently, they continue to be parts of a single unidimensional reality, which is concern about appearance on SNs.

\section{Photo Preparation}

This refers to the most obvious of the behaviors related to concern about appearance on SNs: the care taken over photographs. Photo Preparation on SNs can be through internally photographic means (filters, programs, image quality, etc.), which are correlated with ED risk (McLean et al., 2015; Tiggemann et al., 2020), or external means (makeup, choice of location, lighting, etc.) which are also related to ED risk (Chua \& Chang, 2016; Cohen et al., 2018; McLean et al., 2015; Yellowlees et al., 2019). Other questionnaires have addressed elements in this area, such as Cohen et al. (2018), who found that Photo Investment in selfies was related to the risk of ED. Another aspect of care taken over photographs, not addressed by Photo Investment in McLean et al. (2015), is meticulous planning and preparation. The women taking part in the qualitative study by Chua and Chang (2016) reported that rather than spend a lot of time choosing a photograph, they would instead plan it meticulously. This level of preparation was also clear in the study by Yellowlees et al. (2019), in which the number of offline or attempted selfies was related to severe ED symptoms. Care over photos can also be taken by using various technologies for manipulation (McLean et al., 2015; Tiggemann et al., 2020).

\section{Social Comparison}

This area attempts to evaluate social comparison on SNs related to ED (Saiphoo \& Vahedi, 2019). Comparisons on SNs can be with celebrities or influencers, as well as with peers, the latter being a particularly important group in relation to the risk of ED (Fardouly \& Vartanian, 2015). In their experimental work on IG, Jin et al. (2018) found that people who tended to make social comparisons did so regardless of the type of photo (selfie, group selfie, or photos taken by others), and this comparison was much more common between peers. This result was confirmed in the study by Hogue and Mills (2019) which used FB and IG profiles. One form of comparison that is specific to SNs is the possibility of having feedback on what is posted via the number of likes. According to Tiggemann et al. (2018) being preoccupied by the number of likes is closely related to the risk of ED. The importance that SN users place on numerical indicators, either likes or the number of followers, was also identified in the study by Chua and Chang (2016), who found that women saw them as a form of social recognition and recognition of their physical appearance.

\section{Strong Concern About Social Media Presence}

This area avoids assessing concern about the absolute number of followers (or friends on FB), which has produced conflicting results in previous studies (Holland \& Tiggemann, 2016). The aim is to assess the concern about getting more followers regardless of the current number. This area is important as it is an indicator of social prestige and may be used for comparisons (e.g., "I have more followers than someone else"). In addition, it may indirectly increase the impact of images: the more followers a person has, the greater the chances of having interactions via those photos.

\section{Influence of SN Involvement in Day-To-Day Life}

The aim of this area is to evaluate the impact on people's routines of two uses of SNs: Problematic use of SNs and the consequences of concern about appearance on SNs. Problematic use of SNs has consequences, including lack of control, loss of a sense of time, concern about the excessive use of SNs, and general neglect of other activities (Boursier et al., 2020; Charlton \& Danforth, 2007; Van den Eijnden et al., 2016), it has also been related to ED risk (Kamal \& Kamal, 2018). It is also possible to analyze the consequences of concern about appearance on SNs on aspects of people's daily lives, such as spending more time than wanted on the preparation of photos (Chua \& Chang, 2016). 


\section{Concern About Appearance on SNs and ED Risk}

The use of SNs has been linked to ED risk on multiple occasions. In order to better understand this relationship, it is necessary to explain how EDs are conceptualized in this study. The Statistical Manual of Mental Disorders, 5th edition (DSM-5) includes the following disorders in the entry on EDs: Anorexia Nervosa (AN), Bulimia Nervosa (BN), Binge-Eating Disorder (BED), Other Specified Feeding or Eating Disorders (OSFED), and Unspecified Feeding or Eating Disorders (American Psychiatric Association, 2013). These disorders make up a continuum that people move along depending on the point in their lives (Fairburn \& Harrison, 2003). According to Herpertz-Dahlmann (2015), most EDs can be characterized (particularly AN, BN, and some OSFED) by fear of putting on weight and a pathological worry about physical appearance and weight. Although there are significant differences between the types of ED, they have one very important risk factor in common, body dissatisfaction (Stice et al., 2011). In fact, this variable has been widely used in studies examining the relationship between appearance-related SN use (no study to date has assessed concern about appearance on SNs) and ED risk.

Holland and Tiggemann (2016) analyzed 20 studies that related SN use with body image concerns and the risk of $E D$, finding that this relationship existed especially in activities such as uploading photos and seeking negative feedback via status updates. They also found that in experimental studies, FB use caused greater appearance comparison than magazines and other appearance-neutral websites (Fardouly et al., 2015). In addition, this appearance comparison on FB had more negative effects on body satisfaction if comparisons were made with more attractive people (Haferkamp \& Krämer, 2011) or people who weighed less (Lee et al., 2013). In addition, the experimental studies also indicated that FB use was linked to the maintenance of concerns about shape (Mabe et al., 2014). The meta-analysis by Mingoia et al. (2017) found a greater positive correlation between ED risk and appearance-related use of SNs than between ED risk and overall use of SNs.

In short, many studies have linked body dissatisfaction with the appearance-related use of SNs. The theoretical underpinning of why concern about appearance on SNs is related to risk of ED is the exposure to unrealistic images of an ideal of beauty which leads to dissatisfaction with the body (Meier \& Gray, 2014). This effect has already been identified in traditional media such as magazines. However, on SNs there are an almost limitless number of images to compare oneself with (Perloff, 2014), as well as the possibility of modifying images (Hancock \& Toma, 2009; Toma \& Hancock, 2010), of being connected at any time (Tiggemann \& Miller, 2010), and of getting feedback (Moreno \& Koff, 2016).

Given that concern about appearance on SNs is a concept that is related to appearance-related use, we expect that the relationship between concern about appearance on SNs and body dissatisfaction will also be positive. Similarly, we expect the ED risk questionnaire used in this study, the Eating Attitudes Test-26 (EAT-26), to have a positive relationship with concern about appearance on SNs (both the subscales and the overall score). This is because ED risk, evaluated as body dissatisfaction in previous studies, has already been shown to be associated with appearance-related use. In addition, we also differentiate between the EAT-26 subscales in the analysis because, despite not distinguishing between disorders (Mintz \& O'Halloran, 2000), it does differentiate between different risk behaviors, and it will be interesting to determine the relationship of those risk areas with concern about appearance on SNs.

Finally, it is worth highlighting the differences between SNs. Studies about SNs have focused mainly on overall FB use. However, IG is a SN with particular significance for ED risk because it is so image-focused (Fardouly \& Vartanian, 2016). Numerous studies have found relationships between overall IG use and concerns about body image (Fardouly et al., 2017; Feltman \& Szymanski, 2018; Hendrickse et al., 2017), with this relationship being more pronounced with appearance-related use (jin et al., 2018), and stronger than on FB (Marengo et al., 2018). Therefore, we expect a stronger relationship between ED and concern about appearance on SNs with IG than with FB due to its focus on images, and the fact that it is used more by young people. 


\section{Method}

\section{Participants}

Data collection was during October 2018. The sample comprised 576 women, aged between 18 and 62 years old $(M=28.88, S D=11.14)$. Snowball sampling selection, a non-probability method, was used to obtain the sample. Participants who did not have or did not use FB and IG were removed from the study. The vast majority were of Spanish nationality (94.1\%). In terms of education, $67.9 \%$ of the participants had university-level qualifications, $13.7 \%$ vocational training, $13.9 \%$ baccalaureate, $2.3 \%$ compulsory secondary education, $1.7 \%$ primary, and $0.5 \%$ other qualifications.

\section{Measuring Instruments}

\section{Eating Attitudes Test-26 (EAT-26)}

The EAT-26 assesses ED risk (Garner et al., 1982). We used the Spanish version by Gandarillas et al. (2003) in the present study. The EAT-26 consists of 26 Likert items with a range from 1 ("never") to 6 ("always"). The items are divided into three subscales: Dieting, Bulimia, and Food Preoccupation and Oral Control, with a total score also being obtained. The Dieting subscale has 13 items about behavior avoiding fattening foods and concerns about thinness (e.g., "I know how many calories there are in the foods I eat"). The Bulimia and Food Preoccupation subscale has 6 items about bulimic behaviors and thoughts about food (e.g., "I vomit after eating"). Finally, the Oral Control subscale has 7 items about self-control of eating and pressure from others to gain weight (e.g., "I try not to eat even if I'm hungry"). The internal consistency (Cronbach's a) is .88 for the total scale,.88 for the Dieting subscale, .77 for Bulimia and Food Preoccupation, and .79 for Oral Control (Gandarillas et al., 2003). We assessed scores for the three subscales, as they were part of the validation by the authors. We also considered a total score as the scores for the three subscales were correlated with each other.

\section{Concern About Appearance in Social Networks (CONAPP)}

The CONAPP questionnaire was developed specifically for this study, and its objective is the evaluation of concern about appearance on SNs. Until now, there has been no measuring instrument for evaluating this construct, so it was necessary to develop a new one. We followed the recommendations in current psychometric literature in constructing it (American Educational Research Association, American Psychological Association, and National Council on Measurement in Education, 2014; Downing, 2006; Downing \& Haladyna, 2006; Drasgow, 2016; Irwing et al., 2018; Lane et al., 2015; Linn, 2011; Muñiz \& Fonseca-Pedrero, 2019; Van der Linden, 2017). To that end, the first step was to define the variable to be measured. We performed a literature review and developed four theoretical areas for concern about appearance on SNs. These content areas were intended to thoroughly sample the construct being evaluated to ensure content validity. At no time were they considered as possible factors or dimensions because the aim was to produce an essentially unidimensional scale, which would allow the production of a global score for the individuals being evaluated (Calderón et al., 2019).

The next step was the construction of a sufficiently broad bank of 52 items to address these theoretical areas. Those items were assessed via two strategies: expert assessment and psychometric analysis. The items were evaluated by an expert in SNs and three experts in psychometry. They used a judgmental approach, evaluating aspects related to the appropriate formulation of items, and their knowledge and expertise, attempting to avoid any kind of ambiguity that items might produce in the participants. If there were doubts raised about any items, they were eliminated. This led to 11 items being removed. With the 41 remaining items, we calculated various psychometric indicators, discarding 10 items with low discriminative power (discrimination indices below .40) and with lower factorial loadings. The final scale comprised 31 items.

The questionnaire was presented to the participants in Spanish. The items had 6 Likert-type response options, 1 being "Never" and 6 "Always." No reversed items were included to avoid the biases that these may produce (Suárez-Alvarez et al., 2018). The formulation of the items was such that it can be used for any SN that has photographic component similar to IG and FB, which is a clear advantage over other SN-use questionnaires that 
have focused solely on FB. The theoretical areas and the final items in each area are: Photo Preparation (items: 7 , $12,4,13,14,23,3,28$, and 21), Strong concern about social media presence (items: 10, 24 and 15), Social comparison (items: 22, 26, 8, 11, 29, 31, 5, 25, 30 and 18), and Influence of SN involvement in day-to-day life (items: 20, 16, 19, 9, $17,1,2,6,27)$.

A short version (CONAPP-S) was created to be used where limitations of time prevent the full scale from being a practical option. It is made up of the ten items with the highest factor loadings: $6,8,10,12,15,16,21,24,25,27$ (Table 1).

Table 1. Questionnaire for Assessing Concern About Appearance on Social Networks (CONAPP).

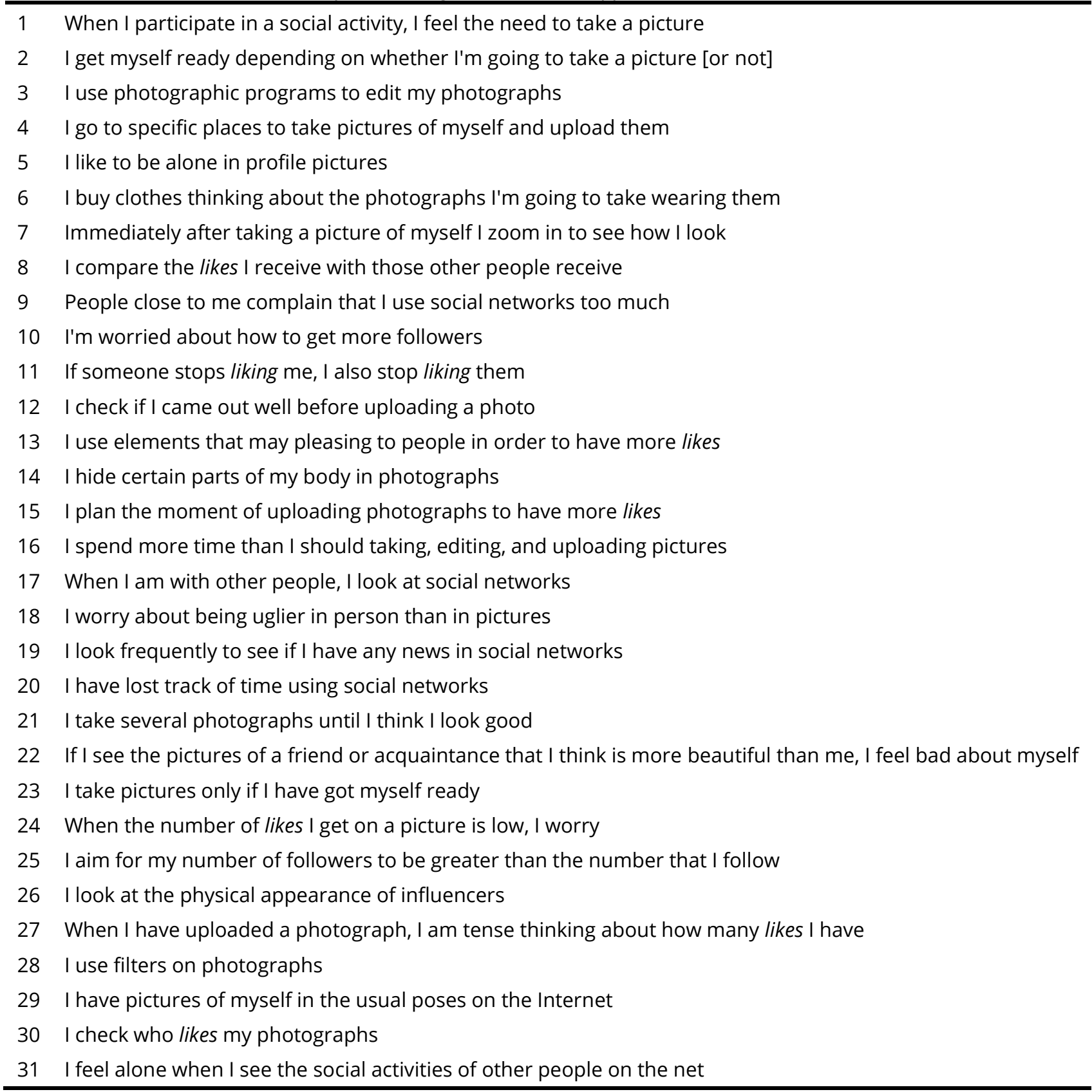

\section{Overall Use of Social Networks}

The assessment of overall use of SNs was carried out using the same question for each of the SNs studied: How much time do you spend looking at FB on any given day? How much time do you spend looking at Instagram on any given day? The question has six categories: I don't have it or I don't use it, Very little time, Some time, Quite a lot of time, A lot of time, And Too much time. For the analyses, scores from 1 to 6 were assigned to each of the categories of the scale. 


\section{Procedure}

The participants completed the online survey anonymously and voluntarily, giving their informed consent before starting. Participants were initially contacted through various SN pages and sites.

\section{Data Analysis}

The psychometric properties of the tests used were analyzed, both from the perspective of classical theory and item response theory (Muñiz, 2018). We used exploratory factor analysis (EFA) to study the internal structure using unweighted least squares (Lloret-Segura et al., 2014). We chose EFA because in this first validation study for the instrument, the authors believed it was a risk to pose strict hypotheses about the dimensionality of the instrument, as a CFA would require. We used a Polychoric Correlation Matrix between items because the items were Likert type and the distribution did not exhitit normality. The procedure for determining the number of factors was the optimal implementation of parallel analysis (PA) (Timmerman \& Lorenzo-Seva, 2011). We estimated reliability using the Cronbach (1951) a coefficient, and McDonald's (1999) $\omega$ coefficient. Within the item response theory (IRT) framework, we estimated reliability using the information function.

We used Pearson correlations to examine the relationship between concern about appearance on SNs and ED risk, and performed stepwise multiple linear regression taking the scores in EAT-26 as the criterion variable and using age, FB use, IG use, and CONAPP as predictor variables. Partial correlations were calculated between IG and FB use and ED risk, controlling for the effect of CONAPP. For the IRT analyses, we used Samejima's (1997) Graded Response Model. The EFA was carried out using the FACTOR program (10.10.01 version) (Lorenzo-Seva \& Ferrando, 2006). The IRTPRO (4.2 version) (Muraki \& Bock, 2003) was used for the IRT analyses. The other analyses were performed using the SPSS statistical package (version 22.0).

\section{Results}

\section{Psychometric Properties of the CONAPP Questionnaire}

Table 2 shows the descriptive statistics of the CONAPP test items. All the discrimination indices (DI) were above .40 since the original items with lower values were eliminated in order to enhance the unidimensionality of the questionnaire, and thus allow a global score to be produced. IRT-a parameter values ranged from .88 to 2.36.

Figure 1. Information Function of the CONAPP Questionnaire.

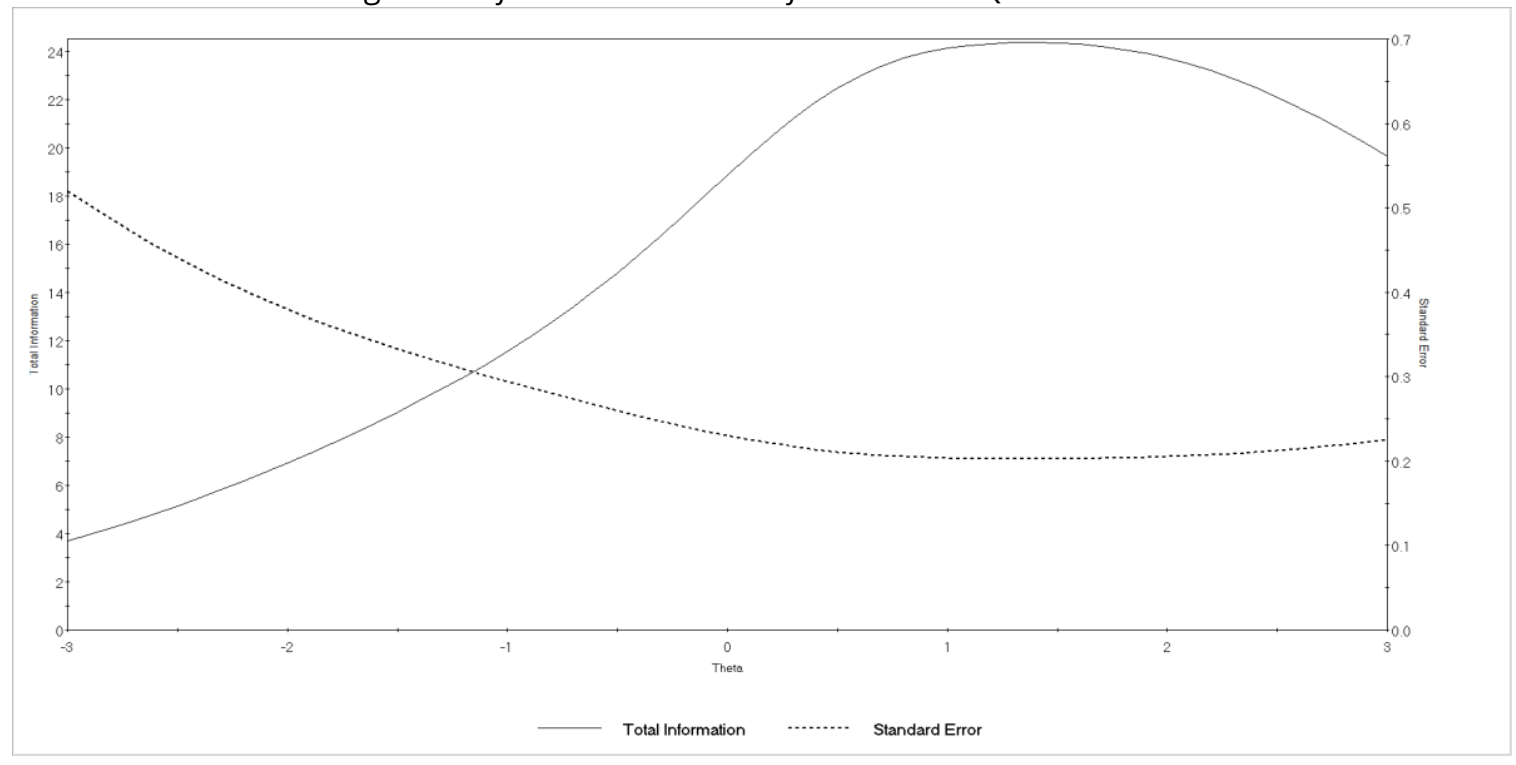

The suitability of the data for factor analysis of the CONAPP scale items was tested with the KMO test (KMO = .94) and the Bartlett test ( $p \leq .001)$. The PA (Calderón et al., 2019; Timmerman \& Lorenzo-Seva, 2011) suggested the presence of a single factor. This result was supported by the GFI indicators (.96), which were greater than .95, indicating a good fit (Ferrando \& Anguiano-Carrasco, 2010); the explained variance (42.06\%); and the RMSR (.08), 
indicating an acceptable fit (Ferrando \& Anguiano-Carrasco, 2010). The factor loadings, shown in Table 2, ranged between .47 and .76 . All these results indicate that the test can be understood as essentially unidimensional (Calderón et al., 2019).

In terms of reliability, the CONAPP had an alpha coefficient of $a=.95$ (Cronbach, 1951), and an omega coefficient of $\omega=.95$ (McDonald, 1999), which can be considered optimal values according to the European model of test quality assessment (Muñiz, 2018). On the other hand, the information function indicates that the CONAPP questionnaire is more accurate for relatively high levels of the trait evaluated (above $\Theta=-1$ ), as Figure 1 shows.

Table 2. Descriptive Statistics and Factor Analysis of the Items of the CONAPP Questionnaire.

\begin{tabular}{|c|c|c|c|c|c|c|c|}
\hline Items & $M$ & $S D$ & Skewness & Kurtosis & Discrimination Index & a & Factor loadings \\
\hline 1 & 2.65 & 1.16 & 0.39 & -0.30 & 0.55 & 1.32 & 0.60 \\
\hline 2 & 2.24 & 1.33 & 0.98 & 0.25 & 0.57 & 1.45 & 0.64 \\
\hline 3 & 2.34 & 1.63 & 1.08 & -0.02 & 0.55 & 1.45 & 0.63 \\
\hline 4 & 1.76 & 1.12 & 1.70 & 2.78 & 0.55 & 1.62 & 0.66 \\
\hline 5 & 3.09 & 1.51 & 0.43 & -0.68 & 0.42 & 1.04 & 0.47 \\
\hline 6 & 1.23 & 0.66 & 3.36 & 12.43 & 0.45 & 1.94 & 0.67 \\
\hline 7 & 3.65 & 1.56 & -0.05 & -0.95 & 0.52 & 1.24 & 0.55 \\
\hline 8 & 1.76 & 1.12 & 1.60 & 2.24 & 0.59 & 1.85 & 0.71 \\
\hline 9 & 1.89 & 1.10 & 1.26 & 1.21 & 0.40 & 0.88 & 0.48 \\
\hline 10 & 1.43 & 0.83 & 2.17 & 4.89 & 0.54 & 1.92 & 0.70 \\
\hline 11 & 1.77 & 1.13 & 1.71 & 2.79 & 0.46 & 1.25 & 0.56 \\
\hline 12 & 4.46 & 1.69 & -0.70 & -0.83 & 0.60 & 1.74 & 0.69 \\
\hline 13 & 1.81 & 1.07 & 1.48 & 2.12 & 0.53 & $1-42$ & 0.62 \\
\hline 14 & 2.41 & 1.42 & 0.84 & -0.04 & 0.43 & 0.97 & 0.47 \\
\hline 15 & 2.02 & 1.49 & 1.30 & 0.52 & 0.66 & 2.31 & 0.77 \\
\hline 16 & 1.39 & 0.83 & 2.40 & 6.72 & 0.58 & 2.36 & 0.76 \\
\hline 17 & 2.79 & 1.05 & 0.62 & 0.54 & 0.49 & 1.08 & 0.52 \\
\hline 18 & 1.82 & 1.34 & 1.80 & 2.44 & 0.46 & 1.36 & 0.58 \\
\hline 19 & 3.34 & 1.28 & 0.06 & -0.60 & 0.61 & 1.50 & 0.65 \\
\hline 20 & 2.65 & 1.31 & 0.48 & -0.50 & 0.53 & 1.20 & 0.58 \\
\hline 21 & 3.26 & 1.59 & 0.17 & -1.01 & 0.69 & 1.93 & 0.74 \\
\hline 22 & 1.70 & 1.14 & 1.86 & 3.18 & 0.48 & 1.37 & 0.59 \\
\hline 23 & 2.20 & 1.33 & 1.08 & 0.55 & 0.50 & 1.26 & 0.57 \\
\hline 24 & 1.50 & 0.89 & 2.14 & 5.11 & 0.61 & 2.30 & 0.76 \\
\hline 25 & 1.79 & 1.48 & 1.87 & 2.29 & 0.52 & 1.78 & 0.68 \\
\hline 26 & 2.38 & 1.59 & 0.8 & -0.48 & 0.59 & 1.36 & 0.62 \\
\hline 27 & 1.57 & 1.02 & 2.10 & 4.45 & 0.58 & 2.04 & 0.71 \\
\hline 28 & 2.82 & 1.55 & 0.49 & -0.76 & 0.61 & 1.58 & 0.65 \\
\hline 29 & 1.89 & 1.16 & 1.3 & 1.14 & 0.58 & 1.62 & 0.66 \\
\hline 30 & 2.77 & 1.52 & 0.55 & -0.60 & 0.44 & 1.06 & 0.49 \\
\hline 31 & 1.78 & 1.18 & 1.61 & 2.12 & 0.46 & 1.20 & 0.54 \\
\hline
\end{tabular}

\section{Psychometric Properties of the Short Version CONAPP-S Questionnaire}

The adequacy of the data for factor analysis of the CONAPP-S scale items was tested with the KMO test (KMO = $.90)$ and the Bartlett test $(p \leq .001)$. The PA (Calderón et al., 2019; Timmerman \& Lorenzo-Seva, 2011) suggested the presence of a single factor. This result was supported by the GFI indicators (.99), which were greater than .95, indicating a good fit (Ferrando \& Anguiano-Carrasco, 2010); the explained variance (57.4\%); and the RMSR (.06), indicating an acceptable fit (Ferrando \& Anguiano-Carrasco, 2010). The factor loadings ranged between .62 and 
.79. All these results indicated that the test can be understood as essentially unidimensional (Calderón et al., 2019). The reliability of the CONAPP-S was excellent, giving an alpha coefficient of $a=92$ (Cronbach, 1951), and an omega coefficient of $\omega=.92$ (McDonald, 1999), which are both excellent values according to the European model of test quality assessment (Muñiz, 2018). The Pearson correlation between CONAPP and CONAPP-S was .91 ( $p \leq .001, N$ = 576).

\section{Concern About Appearance on SNs and ED Risk}

Correlations were calculated between the scores of the participants in the CONAPP test, the total score and subscores of the EAT-26, the level of overall FB use, the level of overall IG use, and age (Table 3). The highest correlation was between EAT-TOTAL and CONAPP $(r=.38, p \leq .001)$; the subscale with the highest correlation was Bulimia and Food Preoccupation and CONAPP $(r=.33, p \leq .001)$; the next was Dieting and CONAPP $(r=.33, p \leq .001)$, and the lowest correlation was found between Oral Control and CONAPP $(r=.21, p \leq .001)$.

The correlation between CONAPP scores and overall IG use was high ( $r=.64, p \leq .001)$, while the correlation of CONAPP with overall FB use was low and negative $(r=-.11, p=.008)$. The same tendency occurred to a lesser degree with the EAT-TOTAL score, the IG correlation being low and positive $(r=.13, p=.002)$ and the correlation with FB being negative and very low $(r=-.05, p=.275)$. The subscales followed the same trend. On the other hand, the correlation of EAT-TOTAL with IG was positive on all scales, but rather low: Bulimia and Food Preoccupation ( $r$ $=.15, p \leq .001)$ and Dieting $(r=.10, p=.017)$. Finally, another relationship of interest is the negative correlation that was found, albeit weak, between IG use and FB use $(r=-.11, p=.010)$.

Age was found to be negatively correlated with CONAPP $(r=-.54, p \leq .001)$, and to a lesser extent with EAT-TOTAL $(r=-.13, p=.002)$. In addition, negative correlations were found with all EAT-TOTAL subscales, highlighting the correlation with Bulimia and Food Preoccupation $(r=-.13, p=.002)$ and Oral Control $(r=-.14, p=.001)$. Finally, there was a positive correlation of age with overall FB use $(r=.32, p \leq .001)$, and a strong, negative correlation with overall IG use $(r=-.61, p \leq .001)$.

Table 3. Pearson Correlations Between CONAPP Scores, CONAPP-S Scores, the EAT-26 Questionnaire, Facebook Use, Instagram Use, and Age.

\begin{tabular}{|c|c|c|c|c|c|c|c|c|c|}
\hline & CONAPP & CONAPP-S & $\begin{array}{c}\text { EAT } \\
\text { TOTAL }\end{array}$ & Dieting & Bulimia & $\begin{array}{c}\text { Oral } \\
\text { Control }\end{array}$ & FB & IG & Age \\
\hline \multicolumn{10}{|l|}{ CONAPP } \\
\hline CONAPP-S & $.91^{* *}$ & & & & & & & & \\
\hline EAT TOTAL & $.38^{* *}$ & $.31^{\star \star}$ & & & & & & & \\
\hline Dieting & $.33^{* *}$ & $.25^{* *}$ & $.94^{* *}$ & & & & & & \\
\hline Bulimia & $.33^{* *}$ & $.27^{* \star}$ & $.86^{* *}$ & $.78^{\star \star}$ & & & & & \\
\hline Oral Control & $.21^{\star \star}$ & $.19^{* \star}$ & $.50^{* \star}$ & $.26^{\star \star}$ & .23 & & & & \\
\hline $\mathrm{FB}$ & $-.11^{\star *}$ & $-.19^{* *}$ & -.05 & -.01 & -.03 & $-.12^{\star *}$ & & & \\
\hline IG & $.64^{* *}$ & $.59^{* \star}$ & $.13^{* *}$ & $.10^{*}$ & $.15^{* \star}$ & .06 & $-.11^{* *}$ & & \\
\hline Age & $-.54^{* *}$ & $-.54^{* *}$ & $-.13^{* *}$ & -.06 & $-.13^{* *}$ & $-.14^{* *}$ & $.32^{* \star}$ & $-.61^{* \star}$ & \\
\hline$M$ & 70.19 & 20.43 & 54.06 & 27.19 & 10.62 & 13.58 & 2.62 & 3.20 & 28.88 \\
\hline$S D$ & 22.65 & 7.91 & 17.57 & 10.33 & 5.01 & 4.76 & 1.22 & 1.55 & 11.14 \\
\hline$N$ & 576 & 576 & 576 & 576 & 576 & 576 & 576 & 576 & 576 \\
\hline a & .95 & .92 & .89 & .87 & .81 & .63 & & & \\
\hline
\end{tabular}

Note: EAT TOTAL = EAT Total Score; Dieting = Dieting Subscale; Bulimia = Bulimia and Food Preoccupation Subscale; Oral Control = Oral Control Subscale; CONAPP =Total score of CONAPP; CONAPP-S = Total score of CONAPP-S; FB = Facebook Use; IG = Instagram Use. ${ }^{*} p \leq .050,{ }^{* *} p \leq .010$.

In order to more deeply explore the data in Table 4, we performed a multiple regression analysis, taking the overall EAT-26 scores as the criterion variable and FB use, IG use, age, and concern about appearance on SNs (CONAPP) as predictor variables. The two variables with the greatest weight in the regression model were $\operatorname{CONAPP}(\beta=.50)$ and IG use $(\beta=-.18)$, which explained $40.4 \%$ of the differences in ED risk. 
Table 4. Values of the Stepwise Regression Equation for the Prediction Measured

With the EAT-26 Scale.

\begin{tabular}{lccccccc}
\hline & $R^{2}$ & $F$ & $B$ & $B(95 \% \mathrm{Cl})$ & $S E$ & $\beta$ & $t$ \\
\hline Model 1 EAT TOTAL & .40 & 55.99 & & & & & \\
CONAPP & & & 0.38 & {$[0.31,0.46]$} & .04 & .50 & $10.01^{* *}$ \\
IG use & & & -2.08 & {$[-3.18,0.98]$} & .56 & -.18 & $-3.71^{* *}$ \\
\hline
\end{tabular}

Note: EAT TOTAL = EAT Total Score; CONAPP = Total score of CONAPP; IG = Instagram Use. ${ }^{*} p \leq .050,{ }^{* *} p \leq .010$.

To examine the mediating role of CONAPP in the relationships between FB and IG use and ED risk we calculated the partial correlations between those variables, eliminating the effect of CONAPP. We performed this analysis in order to determine whether people's scores in CONAPP could explain part of the variance of the relationships between IG, FB, and ED risk. The correlation between FB use and ED risk (once the influence of CONAPP was removed) was practically null ( $r=-.004, p=.922)$. This practically-null correlation had already been found without controlling for the effect of CONAPP. For IG the correlation was a little stronger $(r=-.15, p<.001)$. This correlation between IG use and ED risk without controlling for the effect of CONAPP was positive, but when we controlled for the effect of CONAPP, IG use was negatively correlated with ED risk. Thus, the variance explained by CONAPP was so large that without it there was practically no relationship between IG use and ED risk, this effect was less stark for FB use.

\section{Discussion}

The main objective of this study was to examine the relationships between concern about appearance on SNs and ED risk. This general objective was broken down into two more specific objectives. The first was the development and psychometric analysis of a new measuring instrument to assess concern about appearance on SNs (CONAPP) and the second analyzed the relationships between concern about appearance on SNs and the ED risk.

\section{Concern About Appearance on SNs}

With respect to the first objective, the psychometric properties of the questionnaire developed (CONAPP) were adequate: the reliability was excellent, showing an essentially unidimensional structure. Following this first study, it would be useful for future studies to perform confirmatory factor analysis with larger samples. Below, we discuss how the four areas theorized in the final version of CONAPP and CONAPP-S were represented. Following that, we discuss the differences between CONAPP and CONAPP-S in more general terms.

In the final version of CONAPP, the theorized area which was reduced the most was "Strong concern about social media presence". In addition, within the area "Influence of SN involvement on day-to-day life", the items referring to problematic SN use were not very discriminatory. In contrast, the items about consequences of concern about appearance on SNs such as item 16 "I spend more time than I should taking, editing, and uploading photograph" exhibited high discriminatory power. Within the "Photo preparation" area, there was good discriminatory power shown by the item about the use of filters (item 28) and the item about taking various shots before achieving the desired photo (item 21). These behaviors were highlighted in the study by Chua and Chang (2016). However, it is important to note that it is possible that in time, assessing the use of filters will no longer make any sense as they become ubiquitous. The items we retained in the "Social comparison" area indicate the importance of numerical indicators (such as "likes"), as noted in previous studies on the relationship with ED risk (Tiggemann et al., 2018). The shorter CONAPP-S scale, made up of the items with the highest factorial loading, evaluates the four theorized areas with a similar number of items in each one.

Generally, the less discriminating items referred to very specific actions to achieve certain objectives (i.e., item 14, about hiding certain parts of the body). Those with the highest discriminatory power were 15, 21 and 24, all related to the photographic component and to the number of likes, confirming results found by other authors (Haferkamp \& Krämer, 2011; Tiggemann et al., 2018). This was repeated in the CONAPP-S in which almost half of the items were about likes and many of the remaining items referred to activities related to photos, except for two which were about the numbers of followers. This again highlights the importance of physical comparison via images on SN which has been noted by other studies (Fardouly \& Vartanian, 2015), along with the numerical indicators such 
as likes (Mabe et al., 2014). It may seem that the two items about numbers of followers are unconnected to images and likes. However, it is another form of social prestige (Chua \& Chang, 2016) which could indirectly affect the number of likes (the more followers one has, the more likely that one's photos will be seen).

In short, the new instrument and its short version allow for reliable, valid assessment of concern about appearance, which will be of great help for the development of future research and for the formulation of prevention programs. The CONAPP questionnaire has the advantage over other questionnaires of analyzing concern about appearance on SNs more thoroughly and considering all of the behaviors that might be part of this construct. Other questionnaires include The Facebook Questionnaire (Meier \& Gray, 2014), which focuses on more specific photographic activities and the questionnaire from McLean et al. (2015), which includes the Photo Investment scale (effort made in choosing photos) and Photo Manipulation (technological manipulation of images). Both the short and long CONAPP questionnaires demonstrated adequate properties. The difference between them is that the long form allows a more thorough exploration of concern about appearance on SNs, whereas the short version would be recommended when there is not enough time available for a more detailed evaluation.

\section{Concern About Appearance on SNs and ED Risk}

The second objective was to examine the relationship between concern about appearance on SNs, evaluated through the CONAPP questionnaire and ED risk, estimated using the EAT-26 questionnaire. We begin by explaining the relationship between concern about appearance on SNs and ED risk, which is the principal result. Following that, we discuss the relationships between the general use of IG and FB, concern about appearance on SNs, ED risk, and age.

We found that people with a high concern about appearance on SNs tended to have a higher risk of ED. We also saw that concern about appearance explained part of the relationship between IG use and ED risk, as the association between IG use and ED risk disappears once the effect of CONAPP is controlled for. This effect only occurred with IG, not with FB. The relationship between FB use and ED risk was practically null, whether the effect of CONAPP was controlled for or not. This may be because FB use has no relationship with ED risk as it is a less image-focused SN (Marengo et al., 2018) and has older users (Global Digital Report, 2019), whereas IG use is related to ED risk because it is more image focused (Marengo et al., 2018) and its users tend to be younger (Global Digital Report, 2019). This is in line with previous research (Cohen et al., 2018), although it is worth noting that in our study, we used a stricter measure of ED risk compared to other studies which used body dissatisfaction (Saiphoo \& Vahedi, 2019). This positive relationship indicates that preventive programs should be aimed at SNs behaviors that are pathologically focused on the image, rather than the time of use, which is complicated to estimate (Junco, 2013). To better understand this relationship between concern about appearance on SNs and risk of ED, it would be interesting for future studies to combine data from questionnaires with data directly extracted from SNs, as is starting to be done with the analysis of content in SNs (Ramiandrisoa, \& Mothe, 2020).

We also examined the relationships between the general use of IG and FB in relation to concern about appearance on SNs, risk of ED, and age. The main conclusion that we can draw is that, compared to FB, IG is used by younger people, with greater ED risk, and with more concern about appearance on SNs. However, this result should be taken with caution owing to the way FB and IG use was measured, based on subjective estimated time ("I spend little time on it") rather than on an objective measure of time spent using it. These results are in line with previous studies which have noted that young women, who have a higher ED risk, tend to use more image-focused SNs (Kim \& Chock, 2015; Striegel-Moore et al., 2003; Taylor et al., 2006).

The fact that younger women use IG more and their body image is more affected may be due to the age of the ideal women presented in these SNs. On IG, the images of ideal women are images of young women, so it is younger women who find an ideal to compare themselves with, provoking body dissatisfaction. This effect has been confirmed in traditional media such as magazines (Bessenoff \& Del Priore, 2007). Another possible reason for young women using IG more and having greater risks of ED is that they are within the onset age for ED which is approximately 18 years old (Volpe et al., 2016). In short, this result indicates that there is a clear at-risk population defined in a specific SN context: highly-visual SNs such as IG. Therefore, future studies and prevention strategies for inappropriate use of SNs should focus on this population and context of SN use. 


\section{Limitations}

These results should be interpreted in the light of a number of limitations. Future studies should address following accounts on SNs related to sports or food, as that is related to ED risk (Cohen et al., 2017). It would also be interesting in future research to include more indicators on influencers, since this is a widespread phenomenon and has already been shown to correlate with ED risk (Cohen et al., 2017). In addition, no men were included in the sample, however, it would be useful to include them in future research, as there are already data indicating that men's use of SNs is also related to ED risk (De Vries et al., 2016). It is also possible that the relationships we found were weakened by the strict measurement of ED outcomes, as we used an ED screening questionnaire (EAT26). In addition, the measures of general use of FB and IG may be distorted as it was measured based on subjective estimated time ("I spend little time on it").

\section{Conclusions}

A new questionnaire has been developed to assess concern about appearance on social networks (SNs). The new instrument consists of 31 Likert-type items and shows an essentially unidimensional structure and excellent reliability. Clear relationships were found between the level of concern about appearance on SNs shown by the participants and eating disorder (ED) risk. The results indicate that people with a high concern about appearance on SNs, measured via the Concern About Appearance Questionnaire (CONAPP), tend to have a higher risk of ED. Younger people have more concern about appearance on SNs, with IG use being more prominent than FB use. In fact, FB and IG work very differently, IG is used by younger people, with a higher probability of ED risk and higher concern about appearance on SNs. In contrast, FB is used by older people, with a lower probability of ED risk and a lower concern about appearance on SNs. These results are important for future research and the design of preventive programs, which should focus on IG or highly-visual SNs, younger people, and maladaptive behaviors in $\mathrm{SN}$ use, rather than simply attempting to reduce the overall use of SNs.

\section{Acknowledgement}

This work was supported by a predoctoral grant from the Principality of Asturias (BP19-032) and the Spanish Ministry of Science Innovation and Universities (PSI2017-85724-P).

\section{References}

American Educational Research Association, American Psychological Association, and National Council on Measurement in Education. (2014). Standards for educational and psychological testing. American Psychological Association.

American Psychiatric Association. (2013). Diagnostic and statistical manual of mental disorders: DSM-5 ${ }^{\mathrm{TM}}$ (5th ed.). American Psychiatric Publishing, Inc.

Bessenoff, G. R., \& Del Priore, R. E. (2007). Women, weight, and age: Social comparison to magazine images across the lifespan. Sex Roles, 56(3-4), 215-222. http://dx.doi.org/10.1007/s11199-006-9164-2

Boursier, V., Gioia, F., \& Griffiths, M. D. (2020). Do selfie-expectancies and social appearance anxiety predict adolescents' problematic social media use? Computers in Human Behavior, 110, Article 106395.

https://doi.org/10.1016/j.chb.2020.106395

Burnell, K., George, M. J., Vollet, J. W., Ehrenreich, S. E., \& Underwood, M. K. (2019). Passive social networking site use and well-being: The mediating roles of social comparison and the fear of missing out. Cyberpsychology: Journal of Psychosocial Research on Cyberspace, 13(3), Article 5. http://dx.doi.org/10.5817/CP2019-3-5

Calderón, C., Navarro, D., Lorenzo-Seva, U., \& Ferrando, P. J. (2019). Multidimensional or essentially unidimensional? A multi-faceted factor analytic approach for assessing the dimensionality of tests and items. Psicothema, 31(4), 450-457. https://doi.org/10.7334/psicothema2019.153 
Charlton, J. P., \& Danforth, I. D. W. (2007). Distinguishing addiction and high engagement in the context of online game playing. Computers in Human Behavior, 23(3), 1531-1548. https://doi.org/10.1016/j.chb.2005.07.002

Chua, T. H. H., \& Chang, L. (2016). Follow me and like my beautiful selfies: Singapore teenage girls' engagement in self-presentation and peer comparison on social media. Computers in Human Behavior, 55(Part A), 190-197. https://doi.org/10.1016/j.chb.2015.09.011

Cohen, R., \& Blaszczynski, A. (2015). Comparative effects of Facebook and conventional media on body image dissatisfaction. Journal of Eating Disorders, 3, Article 23. https://doi.org/10.1186/s40337-015-0061-3

Cohen, R., Newton-John, T., \& Slater, A. (2017). The relationship between Facebook and Instagram appearancefocused activities and body image concerns in young women. Body Image, 23, 183-187.

https://doi.org/10.1016/j.bodyim.2017.10.002

Cohen, R., Newton-John, T., \& Slater, A. (2018). 'Selfie'-objectification: The role of selfies in self-objectification and disordered eating in young women. Computers in Human Behavior, 79, 68-74.

https://doi.org/10.1016/j.chb.2017.10.027

Cronbach, L. J. (1951). Coefficient alpha and the internal structure of tests. Psychometrika, 16(3), 297-334. https://doi.org/10.1007/BF02310555

De Vries, D. A., Peter, J., de Graaf, H., \& Nikken, P. (2016). Adolescents' social network site use, peer appearancerelated feedback, and body dissatisfaction: Testing a mediation model. Journal of Youth and Adolescence, 45(1), 211-224. https://doi.org/10.1007/s10964-015-0266-4

Downing, S. M. (2006). Twelve steps for effective test development. In S. M. Downing \& T. M. Haladyna (Eds.), Handbook of test development (pp. 3-25). Lawrence Erlbaum Associates.

Downing, S. M., \& Haladyna, T. M. (2006). Handbook of test development. Lawrence Erlbaum Associates.

Drasgow, F. (Ed.). (2016). Technology and testing. Routledge

Fairburn, C. G. \& Harrison, P. J. (2003). Eating disorders. The Lancet, 361(9355), 407-416.

https://doi.org/10.1016/S0140-6736(03)12378-1

Fardouly, J., Diedrichs, P. C., Vartanian, L. R., \& Halliwell E. (2015). Social comparisons on social media: The impact of Facebook on young women's body image concerns and mood. Body Image, 13, 38-45.

https://doi.org/10.1016/j.bodyim.2014.12.002

Fardouly, J., \& Vartanian, L. R. (2015). Negative comparisons about one's appearance mediate the relationship between Facebook usage and body image concerns. Body Image, 12, 82-88.

https://doi.org/10.1016/j.bodyim.2014.10.004

Fardouly, J., \& Vartanian, L. R. (2016). Social media and body image concerns: Current research and future directions. Current Opinion in Psychology, 9, 1-5. https://doi.org/10.1016/j.copsyc.2015.09.005

Fardouly, J., Willburger, B. K., \& Vartanian, L. R. (2017). Instagram use and young women's body image concerns and self-objectification: Testing mediational pathways. New Media \& Society, 20(4), 1380-1395.

https://doi.org/10.1177/1461444817694499

Feltman, C. E., \& Szymanski, D. M. (2018). Instagram use and self-objectification: The roles of internalization, comparison, appearance commentary and feminism. Sex Roles, 78(5-6), 311-324.

https://doi.org/10.1007/s11199-017-0796-1 
Ferrando, P. J., \& Anguiano-Carrasco, C. (2010). El análisis factorial como técnica de investigación en psicología [Factor analysis as a research technique in psychology]. Papeles del Psicólogo, 31(1), 18-33.

http://www.papelesdelpsicologo.es/English/1793.pdf

Gandarillas, A., Zorrilla, B., Sepúlveda, A. R., \& Muñoz, P. E. (2003). Trastornos del comportamiento alimentario. Prevalencia de casos clínicos en mujeres adolescentes de la Comunidad de Madrid (Documentos Técnicos de Salud Pública No. 85) [Eating behavior disorders. Prevalence of clinical cases in adolescent women of the Community of Madrid (Public Health Technical Documents No. 85)]. http://psiqu.com/2-6555

Garner, D. M., Olmsted, M. P., Bohr, Y., \& Garfinkel, P. E. (1982). The Eating Attitudes Test: Psychometric features and clinical correlates. Psychological Medicine, 12(4), 871-878. https://doi.org/10.1017/S0033291700049163

Global Digital Report. (2019). Digital 2019: Essential insights into how people around the world use the internet, mobile devices, social media and e-commerce. https://hootsuite.com/pages/digital-in-2019

Grabe, S., Ward, L. M., \& Hyde, J. S. (2008). The role of the media in body image concerns among women: A metaanalysis of experimental and correlational studies. Psychological Bulletin, 134(3), 460-476.

https://doi.org/10.1037/0033-2909.134.3.460

Haferkamp, N., \& Krämer, N. C. (2011). Social comparison 2.0: Examining the effects of online profiles on socialnetworking sites. Cyberpsychology, Behavior, and Social Networking, 14(5), 309-314.

https://doi.org/10.1089/cyber.2010.0120

Hancock, J. T., \& Toma, C. L. (2009). Putting your best face forward: The accuracy of online dating photographs. Journal of Communication, 59(2), 367-386. https://doi.org/10.1111/j.14602466.2009.01420.x

Hendrickse, J., Arpan, L. M., Clayton, R. B., \& Ridgway, J. L. (2017). Instagram and college women's body image: Investigating the roles of appearance-related comparisons and intrasexual competition. Computers in Human Behavior, 74, 92-100. https://doi.org/10.1016/j.chb.2017.04.027

Herpertz-DahImann, B. (2015). Adolescent eating disorders: Update on definitions, symptomatology, epidemiology, and comorbidity. Child and Adolescent Psychiatric Clinics, 24(1), 177-196.

https://doi.org/10.1016/j.chc.2014.08.003

Hogue, J. V., \& Mills, J. S. (2019). The effects of active social media engagement with peers on body image in young woman. Body Image, 28, 1-5. https://doi.org/10.1016/j.bodyim.2018.11.002

Holland, G., \& Tiggemann, M. (2016). A systematic review of the impact of the use of social networking sites on body image and disordered eating outcomes. Body Image, 17, 100-110.

https://doi.org/10.1016/j.bodyim.2016.02.008

Hummel, A. C., \& Smith, A. R. (2015). Ask and you shall receive: Desire and receipt of feedback via Facebook predicts disordered eating concerns. International Journal of Eating Disorders, 48(4), 436-442.

https://doi.org/10.1002/eat.22336

Irwing, P., Booth, T., \& Hughes, D. J. (Eds.). (2018). The Wiley handbook of psychometric testing: A multidisciplinary reference on survey, scale and test development. Wiley-Blackwell.

Jin, S. V., Ryu, E., \& Muqaddam, A. (2018). Dieting 2.0!: Moderating effects of Instagrammers' body image and Instafame on other Instagrammers' dieting intention. Computers in Human Behavior, 87, 224-237.

https://doi.org/10.1016/j.chb.2018.06.001

Junco, R. (2013). Comparing actual and self-reported measures of Facebook use. Computers in Human Behavior, 29(3), 626-631. https://doi.org/10.1016/j.chb.2012.11.007 
Kamal, N. N., \& Kamal, N. N. (2018). Determinants of problematic Internet use and its association with disordered eating attitudes among Minia university students. International Journal of Preventive Medicine, 9(1), Article 35. https://doi.org/10.4103/ijpvm.IJPVM_489_17

Kim, J. W., \& Chock, T. M. (2015). Body image 2.0: Associations between social grooming on Facebook and body image concerns. Computers in Human Behavior, 48, 331-339. http://dx.doi.org/10.1016/j.chb.2015.01.009

Lane, S., Raymond, M. R., Haladyna, T. M., \& Downing, S. M. (2015). Test development process. In S. Lane, M. R. Raymond, \& T. M. Haladyna (Eds.), Handbook of test development (2nd ed., pp. 3-18). Lawrence Erlbaum Associates.

Lee, H. E., Taniguchi, E., Modica, A., \& Park, H. (2013). Effects of witnessing fat talk on body satisfaction and psychological well-being: A cross-cultural comparison of Korea and the United States. Social Behavior and Personality: An International Journal, 41(8), 1279-1295. https://doi.org/10.2224/sbp.2013.41.8.1279

Linn, R. L. (2011). The standards for educational and psychological testing. In S. M. Downing \& T. M. Haladyna (Eds.), Handbook of test development (pp. 41-52). Lawrence Erlbaum Associates.

Lloret-Segura, S., Ferreres-Traver, A., Hernández-Baeza, A., \& Tomás-Marco, I. (2014). The exploratory factor analysis of items: guided analysis based on empirical data and software. Anales de Psicología, 30(3), 1151-1169. https://doi.org/10.6018/analesps.30.3.199361

Lorenzo-Seva, U., \& Ferrando, P. J. (2006). FACTOR: A computer program to fit the exploratory factor analysis model. Behavior Research Methods, 38(1), 88-91. https://doi.org/10.3758/BF03192753

Mabe, A. G., Forney, K. J., \& Keel, P. K. (2014). Do you "like" my photo? Facebook use maintains eating disorder risk. International Journal of Eating Disorders, 47(5), 516-523. https://doi.org/10.1002/eat.22254

Marengo, D., Longobardi, C., Fabris, M. A., \& Settanni, M. (2018). Highly-visual social media and internalizing symptoms in adolescence: The mediating role of body image concerns. Computers in Human Behavior, 82, 63-69. https://doi.org/10.1016/j.chb.2018.01.003

McDonald, R. P. (1999). Test theory: A unified treatment. Lawrence Erlbaum Associates.

McLean, S. A., Paxton, S. J., Wertheim, E. H., \& Masters, J. (2015). Photoshopping the selfie: Self photo editing and photo investment are associated with body dissatisfaction in adolescent girls. International Journal of Eating Disorders, 48(8), 1132-1140. https://doi.org/10.1002/eat.22449

Meier, E. P., \& Gray, J. (2014). Facebook photo activity associated with body image disturbance in adolescent girls. Cyberpsychology, Behavior, and Social Networking, 17(4), 199-206. https://doi.org/10.1089/cyber.2013.0305

Mingoia, J., Hutchinson, A. D., Wilson, C., \& Gleaves, D. H. (2017). The relationship between social networking site use and the internalization of a thin ideal in females: A meta-analytic review. Frontiers in Psychology, 8, Article 1351. https://doi.org/10.3389/fpsyg.2017.01351

Mintz, L. B., \& O'Halloran, M. S. (2000). The Eating Attitudes Test: Validation with DSM-IV eating disorder criteria. Journal of Personality Assessment, 74(3), 489-503. https://doi.org/10.1207/S15327752JPA7403_11

Moreno, M. A., \& Koff, R. (2016). Media theories and the Facebook influence model. In G. Riva, B. K. Wiederhold, \& P. Cipresso (Eds.), The psychology of social networking: Personal experience in online communities (pp. 130-142). De Gruyter Open Poland. https://doi.org/10.1515/9783110473780-013

Muñiz, J. (2018). Introducción a la psicometría [Introduction to psychometry]. Pirámide. 
Muñiz, J., \& Fonseca-Pedrero, E. (2019). Diez pasos para la construcción de un test [Ten steps in building a test]. Psicothema, 31(1), 7-16. https://doi.org/10.7334/psicothema2018.291

Muraki, E., \& Bock, R. D. (2003). PARSCALE 4 for Windows: IRT based test scoring and item analysis for graded items and rating scales (4.20 version) [Computer software]. Scientific Software International, Inc.

Perloff, R. M. (2014). Social media effects on young women's body image concerns: Theoretical perspectives and an agenda for research. Sex Roles, 71(11-12), 363-377. https://doi.org/10.1007/s11199-014-0384-6

Ramiandrisoa, F., \& Mothe, J. (2020). Early detection of depression and anorexia from social media: A machine learning approach. In Proceedings of the Conference CIRCLE 2020. HAL. https://hal.archives-ouvertes.fr/hal02877723

Saiphoo, A. N., \& Vahedi, Z. (2019). A meta-analytic review of the relationship between social media use and body image disturbance. Computers in Human Behavior, 101, 259-275. https://doi.org/10.1016/j.chb.2019.07.028

Samejima, F. (1997). Graded response model. In W. J. Van der Linden. \& R. K. Hambleton (Eds.), Handbook of modern item response theory (pp. 85-100). Springer.

Smith, A., \& Anderson, M. (2018). Social media use in 2018. Pew Research Center.

https://www.pewinternet.org/2018/03/01/social-media-use-in-2018

Stice, E., Marti, C. N., \& Durant, S. (2011). Risk factors for onset of eating disorders: Evidence of multiple risk pathways from an 8-year prospective study. Behaviour Research and Therapy, 49(10), 622-627.

https://doi.org/10.1016/j.brat.2011.06.009

Striegel-Moore, R. H., Dohm, F. A., Kraemer, H. C., Taylor, C. B., Daniels, S., Crawford, P. B., \& Schreiber, G. B. (2003). Eating disorders in white and black women. American Journal of Psychiatry, 160(7), 1326-1331.

https://doi.org/10.1176/appi.ajp.160.7.1326

Striegel-Moore, R. H., Rosselli, F., Perrin, N., DeBar, L., Wilson, G. T., May, A., \& Kraemer, H. C. (2009). Gender difference in the prevalence of eating disorder symptoms. International Journal of Eating Disorders, 42(5), 471474. https://doi.org/10.1002/eat.20625

Suárez-Alvarez, J., Pedrosa, I., Lozano, L. M., García-Cueto, E., Cuesta, M., \& Muñiz, J. (2018). Using reversed items in Likert scales: A questionable practice. Psicothema, 30(2), 149-158. https://doi.org/10.7334/psicothema2018.33

Taylor, C. B., Bryson, S., Luce, K. H., Cunning, D., Doyle, A. C., Abascal, L. B., Rockwell, R., Dev, P., Winzelberg, A. J., \& Wilfley, D. E. (2006). Prevention of eating disorders in at-risk college-age women. Archives of General Psychiatry, 63(8), 881-888. https://doi:10.1001/archpsyc.63.8.881

Tiggemann, M., Anderberg, I., \& Brown, Z. (2020). Uploading your best self: Selfie editing and body dissatisfaction. Body Image, 33, 175-182. https://doi.org/10.1016/j.bodyim.2020.03.002

Tiggemann, M., \& Barbato, I. (2018). “You look great!": The effect of viewing appearance-related Instagram comments on women's body image. Body Image, 27, 61-66. https://doi.org/10.1016/j.bodyim.2018.08.009

Tiggemann, M., Hayden, S., Brown, Z., \& Veldhuis, J. (2018). The effect of Instagram "likes" on women's social comparison and body dissatisfaction. Body Image, 26, 90-97. https://doi.org/10.1016/j.bodyim.2018.07.002

Tiggemann, M., \& Miller, J. (2010). The Internet and adolescent girls' weight satisfaction and drive for thinness. Sex Roles, 63(1-2), 79-90. https://doi.org/10.1007/s11199-010-9789-z

Timmerman, M. E., \& Lorenzo-Seva, U. (2011). Dimensionality assessment of ordered polytomous items with parallel analysis. Psychological Methods, 16(2), 209-220. https://doi.org/10.1037/a0023353 
Toma, C. L., \& Hancock, J. T. (2010). Looks and lies: The role of physical attractiveness in online dating selfpresentation and deception. Communication Research, 37(3), 335-351.

https://doi.org/10.1177/0093650209356437

Van den Eijnden, R. J. J. M., Lemmens, J. S., \& Valkenburg, P. M. (2016). The Social Media Disorder Scale. Computers in Human Behavior, 61, 478-487. https://doi.org/10.1016/j.chb.2016.03.038

Van der Linden, W. J. (Ed.). (2017). Handbook of item response theory. Chapman \& Hall/CRC.

Volpe, U., Tortorella, A., Manchia, M., Monteleone, A. M., Albert, U., \& Monteleone, P. (2016). Eating disorders: What age at onset? Psychiatry Research, 238, 225-227. https://doi.org/10.1016/j.psychres.2016.02.048

Yellowlees, R., Dingemans, A. E., Veldhuis, J., \& de Vaate, A. J. D. B. (2019). Face Yourself(ie): Investigating selfiebehavior in females with severe eating disorder symptoms. Computers in Human Behavior, 101, 77-83. https://doi.org/10.1016/j.chb.2019.07.018

\section{Correspondence to:}

Covadonga González-Nuevo

University of Oviedo

Plaza Feijoo s/n

Oviedo, 33003

Spain

Email: gonzalezvcovadonga@uniovi.es

gonzalezvcovadonga(at)uniovi.es

Editorial record: First submission received on February 19, 2020. Revisions received on June 1, 2020, November 17, 2020 and February 18, 2021. Accepted for publication on March 31, 2021.

Editor in charge: Lenka Dedkova

\section{About Authors}

Covadonga González-Nuevo is a PhD student with a Severo Ochoa grant at the University of Oviedo. Her research focuses on the assessment of problematic social media use.

Marcelino Cuesta is a full professor in the Department of Psychology at the University of Oviedo. His research focuses on the psychometric field.

José Muñiz is the rector and a full professor at the University of Nebrija. His research has been connected with the psychometric field. 